\title{
Immigration and Adverse Pregnancy Outcomes in an Italian Free Care Hospital
}

\author{
Giuseppe Caruso (D) \\ Eleonora Marcoccia ${ }^{1,2}$ \\ Roberto Brunelli' \\ Miriam Candelieri ${ }^{1}$ \\ Michele Carlo Schiavi (ID) \\ Ilaria Zannini ${ }^{1}$ \\ Seila Perrone' \\ Oriana Capri ${ }^{1}$ \\ Ludovico Muzii ${ }^{1}$ \\ Giuseppina Perrone' \\ Paola Galoppi (1D' \\ 'Department of Maternal and Child \\ Health and Urological Sciences, Sapienza \\ University of Rome, Umberto I Hospital, \\ Rome, Italy; ${ }^{2}$ Department of \\ Experimental Medicine, Sapienza \\ University of Rome, Umberto I Hospital, \\ Rome, Italy
}

Correspondence: Giuseppe Caruso Department of Maternal and Child Health and Urological Sciences, Sapienza University of Rome, Umberto I Hospital, Viale del Policlinico, I55, Rome, 00I6I, Italy Tel +39064463069; +390649972568

Email g.caruso@uniromal.it
Introduction: The ever-increasing wave of immigration in Italy has posed demanding challenges in the management of the new multiethnic obstetric population. The aim of this study was to compare pregnancy and perinatal outcomes between immigrants and the native population in an Italian public hospital.

Materials and Methods: Singleton pregnant women ( $\geq 24$ weeks of gestation) who delivered during a 3-year period in an Italian free care hospital were included. Long-term ( $\geq 2$ years of residence) immigrant patients were divided into 4 groups according to their ethnic origin: Europeans, Asians, Latin Americans, and Africans. Perinatal indicators of obstetric outcomes were collected and compared between immigrants and Italians.

Results: Of the 3556 patients included, 1092 were immigrants and 2464 Italians. The immigrant cohort experienced a higher rate of macrosomia $(1.8 \%$ vs $0.6 \% ; \mathrm{p}=0.001)$, very low birth weight $(1.3 \%$ vs $0.6 \% ; p=0.048)$, very early preterm delivery $(1.4 \%$ vs $0.4 \%$; $\mathrm{p}=0.048)$, and gestational diabetes mellitus $(1.8 \%$ vs $0.5 \% ; \mathrm{p}=003)$ compared with the native population. The overall rate of cesarean sections was greater among Italians $(56 \% \mathrm{vs}$ $45.8 \% ; \mathrm{p}<0.001)$. Among ethnic groups, Europeans and Latin Americans reported a higher rate of preterm delivery $(20.2 \%$ and $19 \%$, respectively; $p<0.001)$. Latin Americans carried also a greater risk of fetal macrosomia $(3.6 \% ; \mathrm{p}<0.008)$, while the rate of very low birth weight was higher among Europeans and Africans $(2 \%$ and $1.8 \%$, respectively; $p<0.04)$.

Conclusion: Obstetricians should pay special attention to the potential disparities in pregnancy outcomes between immigrants and the native population. Future efforts should focus on reducing preterm delivery and glucose dysmetabolism among pregnant immigrants.

Keywords: ethnic disparities, immigration, maternal outcomes, neonatal outcomes, pregnancy

\section{Introduction}

The increasing phenomenon of international migration has led to a greater recognition of the ethnic disparities in obstetric and perinatal healthcare. Immigration has been one of the most relevant phenomena characterizing Italian society of the past 40 years. Over the last decades, Italy has faced, as well as other European societies, a huge wave of incoming immigrants, which has led to a progressive change in the baseline socio-demographic and clinical characteristics of obstetric patients. This epidemiologic shift is gradually having obvious implications on the Italian maternal healthcare, posing a substantial clinical challenge for obstetricians. ${ }^{1}$

Wide inequities in terms of obstetric complications across different ethnic groups have been well documented in the literature. Immigrant women seem to display a higher prevalence of preeclampsia, gestational diabetes, preterm delivery, low birth 
weight, fetal growth restriction, intrauterine fetal demise, maternal mortality, and cesarean section (CS) rate. $^{2-9}$ The underlying etiopathogenetic mechanisms are poorly understood and likely to be multifactorial, including genetic and epigenetic factors, socio-cultural disparities, poor socio-economic status, inadequate lifestyles and nutrition, and different maternal health behaviors and attitudes. ${ }^{10-14}$ Immigrants often encounter linguistic, socio-economic, and political barriers, resulting eventually in reduced access to the healthcare system and increased perinatal morbidity. ${ }^{12-19}$ However, currently available data are controversial, and it remains unclear whether immigrated mothers have different obstetrical outcomes compared with the native population. Indeed, few studies have described the paradox of better perinatal outcomes among immigrants, the so-called "healthy-migrant effect", probably linked to a presumed migratory selection of healthy individuals, along with cultural protective factors and social support. $^{20}$

Italian demographic data showed that the number of native births has significantly decreased over the last 10 years, affecting couples with both native partners more than couples with at least one foreign partner. In 2016, the last Italian demographic report stated that immigrants were approximately 5 million and accounted for $8.6 \%$ of the overall Italian population, as opposed to nearly 2 million in 2005 . Italian newborns from immigrant women were $77,397 .{ }^{20,21}$

The ongoing issue of the ethnic disparities in obstetric healthcare is receiving increasing attention and further research is required to address the underlying mechanisms, in order to better understand and manage the increasingly multiethnic population. Recently, several Italian hospitals have focused their research on the obstetric outcomes of immigrated women compared to the native population; however, results were quite heterogeneous. ${ }^{22-25}$

The aim of the study was to compare pregnancy and perinatal outcomes between long-term ( $\geq 2$ years of residence) immigrant women and the native population in an Italian free care hospital.

\section{Materials and Methods}

This is an observational retrospective study including nulliparous or primiparous singleton pregnant women who delivered starting from 24 weeks of gestational age from January 1, 2017 to December 31, 2019 at the Obstetrical Department of Umberto I Hospital of Rome. Our institution is a tertiary level referral center for all obstetric complications with a neonatal intensive care unit (NICU). All patients provided written informed consent and procedures followed were in accordance with the Helsinki declaration. The present study received ethical approval from the Institutional Review Board of Umberto I Hospital. Demographic and clinical data were retrospectively collected from our hospital admission records.

Only immigrant women who have been resident in Italy for at least 2 years were included. The patients filled in a self-administered multilanguage questionnaire enquiring about sociodemographic data. Spontaneous miscarriages and elective pregnancy terminations were excluded. Twin pregnancies were also excluded to avoid a potential bias in some of the analyzed obstetric indicators, such as birth weight and gestational age at delivery. Immigrant patients were divided into four groups according to their ethnic origin: non-Italian Europeans, Asians, Latin Americans, and Africans. A control group of Italian women admitted to our Department in the same period was provided.

The following perinatal care indicators were evaluated: mode of conception (spontaneous or medically assisted), gestational age (GA) at delivery, birth weight, delivery mode (vaginal delivery versus $\mathrm{CS}$ ). Obstetric complications were divided into maternal and fetal. Maternal complications included: diabetes mellitus (divided into pregestational, gestational $\mathrm{A} 1$ and $\mathrm{A} 2$, according to the White classification $^{26}$ ), pregnancy-induced hypertension (PIH, including gestational hypertension, preeclampsia, eclampsia, and chronic hypertension), placental abruption, placental adhesive disorders (PAD), and post-partum hemorrhage (PPH). Fetal complications included: (a) preterm delivery (PTD), defined as a GA at birth $<37$ weeks, which is subdivided into very early PTD (GA at birth between 24 and 28 weeks), early PTD (GA at birth between 28 and 34 weeks), and late PTD (GA at birth between 34 and 37 weeks); (b) low birth weight (LBW), defined as a birth weight $<2500 \mathrm{~g}$ regardless of gestational age, and very low birth weight (VLBW) when less than $1500 \mathrm{~g}$; (c) macrosomia, defined as a birth weight $\geq 4500 \mathrm{~g}$.

The incidence rates were analyzed using the Fisher exact test. Normality testing was performed to determine whether data were sampled from a Gaussian distribution. The Chi-square test was used to evaluate the association between two categorical variables. The $t$-test and MannWhitney $U$-test were used to compare continuous parametric and nonparametric variables, respectively. Statistical software SPSS version 25.0 was used for all 
the analyses. A $p$ value $<0.05$ was considered statistically significant.

\section{Results}

Of the 3556 patients enrolled, 1092 (30.7\%) were immigrants (Europeans: 495; Asians: 268; Latin Americans: 110; Africans: 219) and 2464 (69.3\%) were Italian. The mean maternal age was $29.31 \pm 5.92$ years among immigrants and $32.59 \pm 5.38$ years among native women $(\mathrm{p}<0.05)$.

Maternal reproductive and neonatal characteristics are summarized in Table 1. No significant differences were found between the two groups regarding the rate of medically assisted conceptions ( $8.6 \%$ vs $9.5 \%$, respectively) and the GA at delivery $(38.74 \pm 2.22$ weeks vs $38.37 \pm 2.50$ weeks, respectively). The overall rate of CS was significantly higher in Italians ( $56 \%$ vs $45.8 \%$; $<<0.001)$. The incidence of repeated CS was $30 \%$ in Italians and $20 \%$ in immigrants. Macrosomia $(1.8 \%$ vs $0.6 \% ; \mathrm{p}=0.001)$ and VLBW $(1.3 \%$ vs $0.6 \%$; $p=0.048)$ were significantly higher in immigrants compared to Italian women. Results from the interethnic analysis reported a significantly higher rate of VLBW in Europeans (2.0\%) and Africans (1.8\%) compared to other groups $(\mathrm{p}<0.04)$ and of macrosomia in Latin Americans $(3.6 \% ; \mathrm{p}<0.008)$ (Figure 1).
Comparison of pregnancy outcomes between immigrants and native women is summarized in Table 2. Preterm delivery occurred in $16 \%$ of immigrants and $13.5 \%$ of Italians. Very early PTD was significantly higher in immigrant than Italian women $(1.4 \%$ vs $0.4 \%$; $\mathrm{p}=0.048)$. No differences were found regarding early and late PTD. The subanalysis of PTD among different ethnic groups revealed a significant difference between Europeans and Latin Americans (20.2\% vs 19\%, respectively) compared with Asians (12.7\%), Africans (9.1\%), and Italians $(13.5 \%)(\mathrm{p}<0.01)$. No significant differences between immigrants and Italians were reported as regards IUGR ( $3.1 \%$ vs $3.3 \%$, respectively), pregestational diabetes $(0.1 \%$ vs $0.2 \%$, respectively), pregnancy-induced hypertension ( $5.1 \%$ vs $5.4 \%$, respectively), PAD $(1.2 \%$ vs $0.9 \%$, respectively), and postpartum hemorrhage ( $1.5 \%$ vs $1.3 \%$, respectively). Finally, gestational diabetes mellitus A2 was significantly higher in immigrants than Italians $(1.8 \%$ vs $0.5 \% ; \mathrm{p}=0.03)$ (Figure 2). Additional ethnic-group specific data are summarized in Supplemental Table 1.

\section{Discussion}

In the present study, we aimed to evaluate the effect of immigration on adverse maternal and perinatal outcomes

Table I Maternal, Reproductive and Neonatal Characteristics

\begin{tabular}{|c|c|c|c|}
\hline Variables & Immigrants $(n=\mid 092)$ & Italians $(n=2464)$ & $p$ value \\
\hline Maternal age (years)* & $29.31 \pm 5.92$ & $32.59 \pm 5.38$ & 0.048 \\
\hline Mode of conception & & & NS \\
\hline Spontaneous & 998 (91.4\%) & 2230 (90.5\%) & \\
\hline ART & 94 (8.6\%) & $234(9.5 \%)$ & \\
\hline GA at delivery (weeks)* & $38.74 \pm 2.22$ & $38.37 \pm 2.50$ & NS \\
\hline Mode of delivery & & & $<0.001$ \\
\hline VD & 537 (49.2\%) & $1030(41.8 \%)$ & \\
\hline OD & 55 (5\%) & $54(2.2 \%)$ & \\
\hline CS & $500(45.8 \%)$ & $1380(56 \%)$ & \\
\hline Birth weight $(\mathrm{g})^{*}$ & $3062.19 \pm 692.34$ & $3056.94 \pm 663.8$ & NS \\
\hline$<1500$ & $14(1.3 \%)$ & $15(0.6 \%)$ & 0.048 \\
\hline $1500-2500$ & $175(16 \%)$ & $396(16.1 \%)$ & NS \\
\hline $2500-4500$ & $883(80.9 \%)$ & $2038(82.7 \%)$ & NS \\
\hline$>4500$ & $20(1.8 \%)$ & $15(0.6 \%)$ & 0.001 \\
\hline \multicolumn{4}{|l|}{ Apgar score } \\
\hline I-minute & $8.15 \pm 1.13$ & $8.12 \pm 1.33$ & NS \\
\hline 5 -minute & $9.15 \pm 1.17$ & $9.27 \pm 0.83$ & NS \\
\hline
\end{tabular}

Note: *Data are expressed as mean \pm standard deviation (SD).

Abbreviations: ART, assisted reproductive technology; CS, cesarean section; GA, gestational age; NS, not significant; VD, vaginal delivery. 

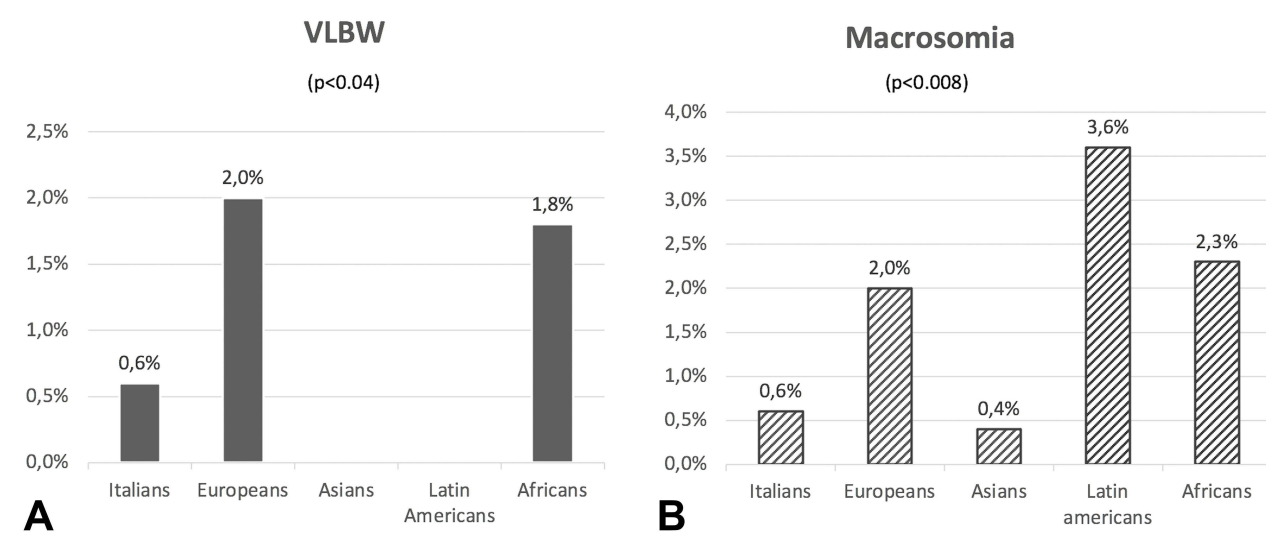

Figure I VLBW (A) and macrosomia (B) among different ethnic groups.

in a reference tertiary Italian public hospital. During the study period, immigrant patients requesting obstetric care were $30.1 \%$ of all patients admitted as opposed to $10 \%$ recorded ten years before. The prevalence was in line with that seen in other European countries, such as Turkish $(32 \%)^{22}$ and Germany $\left.(32.9 \%)\right)^{23}$

We analyzed the obstetric outcomes of 1092 immigrants compared to 2464 native patients, with a glimpse into potential differences in pregnancy complications. In Italy, hospitalization, surgical procedures, and necessary medications are provided free of charge for the immigrant population as established by the health system. However, albeit unlikely, we cannot rule out the financial barrier as a potential underlying risk factor for adverse obstetric outcomes among immigrants. In dealing with this multiethnic obstetric population, we observed that many other factors may have a negative impact on pregnancy outcomes and reduce the quality of care offered, such as poor access to healthcare due to the lack of awareness of its free care nature, delay in looking for prenatal care, missed followups, and communication problems due to the language barrier, among others. An appropriate antenatal care plays a crucial role in facilitating early detection and mitigation of modifiable risk factors during pregnancy.

Table 2 Pregnancy Outcomes in Immigrants and Italians

\begin{tabular}{|l|c|c|c|}
\hline Variables & Immigrants (n= 1092) & Italians (n=2464) & p value \\
\hline PTD & $175(16 \%)$ & $332(13.5 \%)$ & NS \\
Very Early PTD & $15(8.6 \%)$ & $10(3 \%)$ & NS \\
Early PTD & $60(34.3 \%)$ & $108(32.5 \%)$ & NS \\
Late PTD & $100(57.1 \%)$ & $214(64.5 \%)$ & NS \\
\hline IUGR & $34(3.1 \%)$ & $81(3.3 \%)$ & NS \\
\hline Diabetes & $39(3.6 \%)$ & $63(2.6 \%)$ & NS \\
GDM AI & $18(46.2 \%)$ & $44(69.9 \%)$ & 0.03 \\
GDM A2 & $20(51.3 \%)$ & $13(20.6 \%)$ & NS \\
Pregestational & $1(2.6 \%)$ & $6(9.5 \%)$ & NS \\
\hline PIH & $56(5.1 \%)$ & $132(5.4 \%)$ & NS \\
\hline PAD & $13(1.2 \%)$ & $23(0.9 \%)$ & NS \\
Placenta previa & $12(92.3 \%)$ & $21(91.3 \%)$ & NS \\
Placenta accreta & $1(7.7 \%)$ & $2(8.7 \%)$ & NS \\
\hline Placental abruption & $3(0.3 \%)$ & $12(0.5 \%)$ & NS \\
\hline PPH & $16(1.5 \%)$ & $31(1.3 \%)$ & \\
\hline
\end{tabular}

Abbreviations: GMD AI, gestational diabetes mellitus AI (White classification class); GMD A2, gestational diabetes mellitus A2 (White classification class); IUGR, intrauterine growth retardation; NS, not significant; PAD, placental adhesive disorders; PIH, pregnancy-induced hypertension; PPH, post-partum hemorrhage; PTD, preterm delivery. 
GDM A1

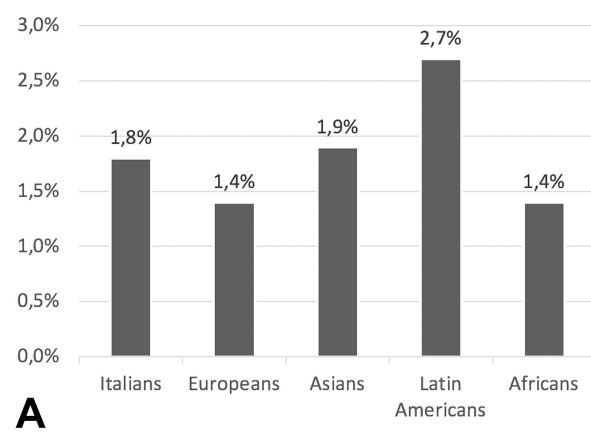

Figure 2 GDM AI (A) and GDM A2 (B) among different ethnic groups.

Improved communication, comprehension and integration would further support immigrant women in accessing prenatal health care.

Recently, several Italian studies concerning the obstetric outcomes of immigrated women compared to the native population have been published, albeit with controversial findings. ${ }^{24-27}$ A retrospective Italian study by Rizzo et al found no significant differences between immigrants and native patients with regard to pregnancy outcomes. ${ }^{24}$ In 2011, Zanconato et al reported significant differences in perinatal outcomes between immigrant and Italian women, the former carrying a higher risk of GA $\leq 32$ weeks at delivery, very low birth weight, and cesarean sections. ${ }^{25}$ Another Italian study by Sosta et al found that preterm delivery occurred more frequently in immigrants, mainly Africans, and was not associated with delayed access to prenatal care. ${ }^{27}$ Finally, Cacciani et al suggested that perinatal outcomes were worse among infants of immigrant mothers, including very PTD, low Apgar score, and need for NICU. ${ }^{28}$ Literature on this topic is scant and there is still no consensus on whether there is a difference in terms of obstetric outcomes between native and immigrant mothers. A putative underlying reason of this controversy is that the studies published so far do not consider the duration of the residence in Italy of immigrant women. Indeed, it was interesting to see a comparison between natives and immigrant mothers living in Italy for a minimum of 2 years and still find significant differences between the two groups. However, it should be underlined that many other variables can explain such differences, such as poor access to healthcare, social integration, genetic predisposition, sociocultural and lifestyle factors, and all these should be further addressed in future, multicenter studies.

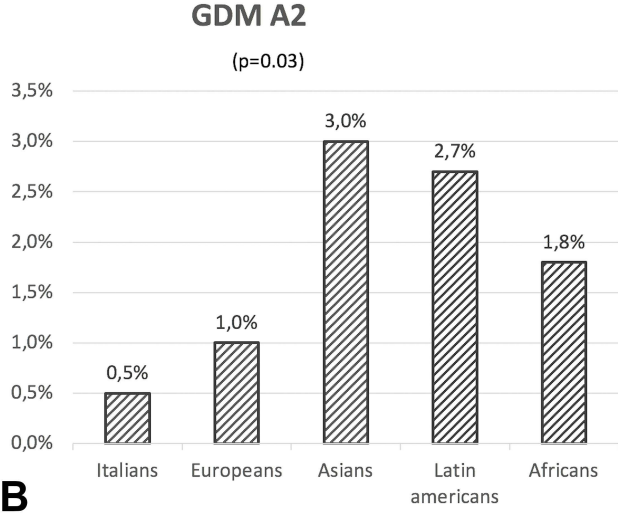

In our study, the maternal age was higher in Italian patients compared to immigrants and this could be linked to delayed reproductive age in Italy due to socio-economic factors. $^{29}$ A two-fold increase in the frequency of very early PTD, which is the most severe adverse outcome, was observed in immigrants as compared to Italian women. Increased PTD rates in immigrants have been reported in several Italian studies and the African mothers seem to be the most affected. ${ }^{25,27}$

The overall incidence of CS in the present study (46$56 \%$ ) is higher than the one recommended in obstetric care (ie, 5-15\% of all births). ${ }^{29,30}$ This could be due to the fact that the rate of vaginal delivery after CS is extremely low in our Department, while repeated CS reach up to $30 \%$ of all $\mathrm{CS}$ and the rate of primary $\mathrm{CS}$ on maternal request is around $8.6 \%{ }^{31}$

Obstetricians should discourage the policy to routinely perform elective CS after a previous one or upon maternal request without an appropriate indication and adequately counsel patients regarding the risks of cesarean sections over vaginal delivery. Controversial data exist in the literature concerning the differences on the CS rate between native and immigrant population. Some studies have found a high rate of CS in the immigrant population. ${ }^{32-34}$ On the other hand, an Italian study by Zanconato et al found that the rate of CS was higher in the native population. ${ }^{25}$ Further information could derive by an accurate analysis of specific CS indications in both Italian and immigrant group.

Since evaluating obstetric outcomes in a heterogeneous immigrant population has its obvious limitations, we also carried out a subanalysis with each of the 4 immigrant groups. Within our study population, Europeans and Latin Americans experienced a greater risk of PTD. Latin 
Americans carried a higher risk of fetal macrosomia, which may be related to poorly controlled gestational diabetes mellitus. ${ }^{35}$ Finally, the rate of VLBW was significantly higher in Europeans and Africans. In the future, it would be interesting to correlate the degree of integration and the duration of residency in Italy with the risk of developing obstetric complications; good integration and long-term residence may exert a positive impact on health of pregnant women and pregnancy outcomes.

The present study contains both limitations and strengths. Limitations include the following topics: (a) the retrospective study design and the intrinsic risk of confounding; (b) the language barrier, which could have led to an incomplete medical history of immigrant and a difficulty in clinical procedure explanation; (c) the lacking data on the socioeconomic status and education level and quality of prenatal care. Strengths are the high number of the population study and the homogeneity of treatment as all patients were referred to the same medical equipe.

There are still complex gaps in the obstetric management of multiethnic pregnant populations. In our experience, immigration demonstrated to be a major risk factor for several adverse obstetric outcomes, such as very low birth weight, macrosomia, very early preterm delivery, gestational diabetes. Italian health professionals in the field of obstetrics should be more sensitive to the issue of migration medicine as the ethnic background can undoubtedly influence the incidence of maternal-fetal complications. In the era of precision medicine, the obstetric behavior should also consider the ethnic-specific risk of developing pregnancy complications. Future efforts should focus on reducing preterm delivery and glucose dysmetabolism among pregnant immigrants in Italy.

\section{Statement of Ethics}

The research was conducted ethically in accordance with the World Medical Association Declaration of Helsinki. Subjects (or their parents or guardians) have given their written informed consent and that the study protocol was approved by the institute's committee on human research.

\section{Author Contributions}

All authors contributed to data analysis, drafting or revising the article, gave final approval of the version to be published, agreed to the submitted journal, and agree to be accountable for all aspects of the work.

\section{Funding}

This research did not receive any specific grant from funding agencies in the public, commercial, or not-forprofit sectors.

\section{Disclosure}

The authors have no conflicts of interest to declare.

\section{References}

1. Di Nicola A, Geraci S. Health transition and immigration: a new challenge for public health. Ann Ig. 2015;27(5):726-736.

2. Khalil A, Rezende J, Akolekar R, Syngelaki A, Nicolaides KH. Maternal racial origin and adverse pregnancy outcome: a cohort study. Ultrasound Obstet Gynecol. 2013;41:278-285. doi:10.1002/ uog. 12313

3. Salihu HM, Kinniburgh BA, Aliyu MH, et al. Racial disparity in stillbirth among singleton, twin, and triplet gestations in the United States. Obstet Gynecol. 2004;104:734-740. doi:10.1097/01. AOG.0000139944.15133.e3

4. Paquier L, Barlow P, Paesmans M, et al. Do recent immigrants have similar obstetrical care and perinatal complications as long-term residents? A retrospective exploratory cohort study in Brussels. BMJ Open. 2020;10(3):e029683. doi:10.1136/bmjopen-2019-029683

5. Manuck TA. Racial and ethnic differences in preterm birth: a complex, multifactorial problem. Semin Perinatol. 2017;41(8):511-518. doi:10.1053/j.semperi.2017.08.010

6. Bryant AS, Worjoloh A, Caughey AB, et al. Racial/ethnic disparities in obstetric outcomes and care: prevalence and determinants. Am J Obstet Gynecol. 2010;202:335-343. doi:10.1016/j.ajog.2009.10.864

7. Holdt Somer SJ, Sinkey RG, Bryant AS. Epidemiology of racial/ ethnic disparities in severe maternal morbidity and mortality. Semin Perinatol. 2017;41(5):258-265. doi:10.1053/j.semperi.2017.04.001

8. Villalonga-Olives E, Kawachi I, von Steinbüchel N. Pregnancy and birth outcomes among immigrant women in the US and Europe: a systematic review. J Immigr Minor Health. 2017;19(6):1469-1487.

9. Alexander GR, Wingate MS, Mor J, et al. Birth outcomes of AsianIndian- Americans. Int $J$ Gynaecol Obstet. 2007;97:215-220. doi:10.1016/j.ijgo.2007.02.017

10. Gould JB, Madan A, Qin C, et al. Perinatal outcomes in two dissimilar immigrant populations in the United States: a dual epidemiologic paradox. Pediatrics. 2003;111:e676-82. doi:10.1542/peds.111.6.e676

11. Guendelman S, Buekens P, Blondel B, et al. Birth outcomes of immigrant women in the United States, France, and Belgium. Matern Child Health J. 1999;3:177-187. doi:10.1023/ A:1022328020935

12. Peláez S, Hendricks KN, Merry LA, et al. Challenges newly-arrived migrant women in Montreal face when needing maternity care: health care professionals' perspectives. Global Health. 2017;13(1):5. doi:10.1186/s12992-016-0229-x

13. Mogos MF, Salinas-Miranda AA, Salemi JL, et al. Pregnancy-related hypertensive disorders and immigrant status: a systematic review and meta- analysis of epidemiological studies. J Immigr Minor Health. 2017;19(6):1488-1497. doi:10.1007/s10903-016-0410-6

14. Kana MA, Correia S, Barros H. Adverse pregnancy outcomes: a comparison of risk factors and prevalence in native and migrant mothers of Portuguese generation XXI birth cohort. $J$ Immigr Minor Health. 2019;21(2):307-314. doi:10.1007/s10903-018-0761-2

15. Healy AJ, Malone FD, Sullivan LM, et al. Early access to prenatal care: implications for racial disparity in perinatal mortality. Obstet Gynecol. 2006;107(3):625-631. doi:10.1097/01. AOG.0000201978.83607.96 
16. Nelson A. Unequal treatment: confronting racial and ethnic disparities in health care. J Natl Med Assoc. 2002;94:666-668.

17. Bollini P, Pampallona S, Wanner P, et al. Pregnancy outcome of migrant women and integration policy: a systematic review of the international literature. Soc Sci Med. 2009;68:452-461. doi:10.1016/ j.socscimed.2008.10.018

18. Holumyong C, Ford K, Sajjanand S, et al. The access to antenatal and postpartum care services of migrant workers in the greater Mekong subregion: the role of acculturative stress and social support. $J$ Pregnancy. 2018;2018:1-12. Article ID: 9241923. doi:10.1155/ 2018/9241923

19. McGlade M, Saha S, Dahlstrom ME. The Latina paradox: an opportunity for restructuring prenatal care delivery. Am J Public Health. 2004;94:2062-2065. doi:10.2105/AJPH.94.12.2062

20. ISTAT. Births and fertility among the resident population 2005-2015. November, 2016.

21. ISTAT. Births and fertility among the resident population. Year 2016; November, 2017.

22. Col Madendag I, Eraslan Sahin M, Madendag Y, et al. The effect of immigration on adverse perinatal outcomes: analysis of experiences at a Turkish tertiary hospital. Biomed Res Int. 2019;2019:2326797. doi:10.1155/2019/2326797

23. Miani C, Ludwig A, Breckenkamp J, et al. Socioeconomic and migration status as predictors of emergency caesarean section: a birth cohort study. BMC Pregnancy Childbirth. 2020;20(1):32. doi:10.1186/s12884-020-2725-5

24. Rizzo N, Ciardelli V, Gandolfi Colleoni G, et al. Delivery and immigration: the experience of an Italian hospital. Eur $J$ Obstet Gynaecol Reprod Biol. 2004;116:170-172. doi:10.1016/j. ejogrb.2004.02.018

25. Zanconato G, Iacovella C, Parazzini F, et al. Pregnancy outcome of migrant women delivering in a public institution in northern Italy. Gynecol Obstet Invest. 2011;72(3):157-162. doi:10.1159/000328318

26. White P. Pregnancy complicating diabetes. Am J Med. 1949;7 (5):609-616. doi:10.1016/0002-9343(49)90382-4
27. Sosta E, Tomasoni LR, Frusca T, et al. Preterm delivery risk in migrants in Italy: an observational prospective study. J Travel Med. 2008;15(4):243-247. doi:10.1111/j.1708-8305.2008.00215.x

28. Cacciani L, Asole S, Polo A, et al. Perinatal outcomes among immigrant mothers over two periods in a region of central Italy. $B M C$ Public Health. 2011;11:294. doi:10.1186/1471-2458-11-294

29. Mills M, Rindfuss RR, McDonald $P$, te Velde E; ESHRE Reproduction and Society Task Force. Why do people postpone parenthood? Reasons and social policy incentives. Hum Reprod Update. 2011;17(6):848-860. doi:10.1093/humupd/dmr026

30. Vogel JP, Betrán AP, Vindevoghel N, et al.; on behalf of the WHO Multi-Country Survey on Maternal and Newborn Health Research Network. Use of the Robson classification to assess caesarean section trends in 21 countries: a secondary analysis of two WHO multicountry surveys. Lancet Glob Health. 2015;3(5):e260-70. doi:10.1016/S2214-109X(15)70094-X

31. Masciullo L, Petruzziello L, Perrone G, et al. Caesarean section on maternal request: an Italian comparative study on patients' characteristics, pregnancy outcomes and guidelines overview. Int $J$ Environ Res Public Health. 2020;17(13):4665. doi:10.3390/ijerph17134665

32. Juárez SP, Small R, Hjern A, et al. Caesarean birth is associated with both maternal and paternal origin in immigrants in Sweden: a population-based study. Paediatr Perinat Epidemiol. 2017;31(6):509-521. doi:10.1111/ppe.12399

33. Merry L, Small R, Blondel B, et al. International migration and caesarean birth: a systematic review and meta-analysis. $B M C$ Pregnancy Childbirth. 2013;13:27. doi:10.1186/1471-2393-13-27

34. Gagnon AJ, Van Hulst A, Merry L, et al. Cesarean section rate differences by migration indicators. Arch Gynecol Obstet. 2013;287 (4):633-639. doi:10.1007/s00404-012-2609-7

35. Pereda J, Bove I, Pineyro MM. Excessive maternal weight and diabetes are risk factors for macrosomia: a cross-sectional study of 42,663 pregnancies in Uruguay. Front Endocrinol. 2020;11:588443. doi: $10.3389 /$ fendo. 2020.588443
International Journal of Women's Health

\section{Publish your work in this journal}

The International Journal of Women's Health is an international, peerreviewed open-access journal publishing original research, reports, editorials, reviews and commentaries on all aspects of women's healthcare including gynecology, obstetrics, and breast cancer. The manuscript management system is completely online and includes a very quick and fair peer-review system, which is all easy to use. Visit http://www.dovepress.com/testimonials.php to read real quotes from published authors. 